\title{
A Cooperação Federativa em Recursos Hídricos: diagnóstico da Bacia Hidro- gráfica do Rio Tramandaí*
}

\begin{tabular}{ll}
\hline & Graduanda em Engenharia de Bioprocessos e \\
& Biotecnologia. Universidade Estadual do Rio \\
& Grande do Sul (UERGS). Av. Bento Gonçalves, \\
Bruna Govoni & 8855. Bairro Agronomia, Porto Alegre, RS, \\
& CEP: 91540-000. \\
& E-mail: bruna.govoni@hotmail.com \\
\hline & Doutor em Recursos Hídricos e Saneamento \\
& Ambiental (UFRG). Professor Adjunto da \\
& Universidade Estadual do Rio Grande do Sul \\
Celmar Corrêa de Oliveira & (UERGS). Av. Bento Gonçalves, 8855. Bairro \\
& Agronomia, Porto Alegre, RS, CEP: 91540-000. \\
& E-mail: celmaroliv@gmail.com \\
\hline
\end{tabular}

* Região Hidrográfica do Litoral : Criado pelo Decreto Estadual no 39.637 e pela Lei Estadual no 10350/94 em 28 de julho de 1999.

Recebido em: 23 ago. 2016. Revisado: 05 dez. 2016. Aceito: 23 dez. 2016. DOI: http://dx.doi.org/10.21674/2448-0479.3.1.7-38

\section{Resumo}

A água é um recurso circulante, fazendo perceptível a interdependência hidrológica, de tal forma que o uso indevido a montante prejudica os usuários a jusante de um corpo hídrico. A gestão dos recursos hídricos alinhada às normas constitucionais e integrada à gestão ambiental tem como foco resolver as questões de escassez relativa desses recursos e assegurar a oferta de água com qualidade à população. Com isto, leva em consideração as demandas quaRev. Elet. Cient. UERGS, v. 3, n. 1, p. 7-38, 2017 
litativas e quantitativas com os limites da disponibilidade hídrica, preservando as funções dos ecossistemas. O objetivo do estudo foi analisar como o emprego da cooperação na Bacia Hidrográfica do Rio Tramandaí pode contribuir na minimização de impactos ambientais e equacionar as questões de escassez desses recursos. $\mathrm{Na}$ pesquisa, optou-se por desenvolver um estudo qualitativo, partindo da hipótese de que a cooperação federativa é subutilizada na área de recursos hídricos, sendo possível considerar o emprego de novas formas de gestão. Adotou-se como referência a metodologia proposta em "Gestão dos Recursos Hídricos Transfronteiriços", em especial, os critérios utilizados para identificar a interdependência hidrológica e os requisitos necessários para a cooperação. Como resultados foram identificados dois problemas: a singularidade negativa do balanço hídrico quantitativo nos meses de dezembro a março e a poluição da Lagoa do Marcelino Ramos. Com a aplicação do método, a cooperação mediante consórcio público e convênio de cooperação mostrou uma relação custo-benefício desfavorável. Ações dos Órgãos ambientais de fiscalização mostram-se necessárias para que obras de trata-mento do esgoto doméstico e a despoluição da Lagoa do Marcelino sejam realizadas.

Palavras-chave: Interdependência Hidrológica. Escassez. Disponibilidade Hídrica.

\section{Abstract}

Federative Cooperation in Water Resources: Tramanhaí River Basin diagnosis

Water is a circulanting resource, allowing detection of hydrological interdependence, such as the upstream misuse that affects down- 
stream users. The management of hydric resources aligned with constitutional norms and integrated with environmental management is intended to solve questions of the relative scarcity of these resources and securing/ensuring the availability of high water quality to the population. It taking in account a way that reconciles the qualitative and quantitative demands of ecosystems with the limits of hydric availability, preserving the functions of those ecosystems. The goal of this study was to analyze how the employment of cooperation in the Tramandaí River watershed could contribute to the minimization of the environmental impacts and addressing questions regarding the scarcity of these resources. In this case, a qualitative study was developed, starting with the hypothesis that institutional cooperation is underutilized in the area of hydric resources, making it possible to employ new forms of management. The methodology proposed in "Gestão dos Recursos Hídricos Transfronteiriços" was adopted as a reference, in particular, the criteria used to identify the hydrological interdependence and the requisites necessary for cooperation. Two problems were identified as results: the unique negative hydric balance in the months from December to March and the polluting of Marcelino Ramos lake. With the application of the method, cooperation mediated by public consortium and cooperation agreement showed an unfavorable cost benefit ratio. The actions of environmental organizations are necessary so that domestic sewage treatment and pollution reduction of Marcelino Ramos lake could be undertaken.

Keywords: Hydrological Interdependence. Scarcity. Water Availability. 


\section{Introdução}

O crescimento populacional fez com que a necessidade da obtenção dos recursos naturais e a ocupação de áreas nativas fossem cada vez maiores. A exploração ininterrupta desses recursos vem sendo um problema ambiental muito grave. $O$ meio ambiente está se esgotado aos poucos, tornando suas riquezas cada vez mais escassas. Um dos recursos naturais mais explorados e agredidos é a água (CURI, 2010). A demanda mundial por este recurso natural indispensável aumentou aproximadamente seis vezes nos últimos dez anos, o que equivale a mais que o dobro da taxa de crescimento demográfico (CURI, 2010).

Entre os países, o Brasil é privilegiado com $12 \%$ da água doce superficial do mundo, possuindo o maior rio existente, o Amazonas, e parte dos maiores reservatórios de água subterrânea do planeta, o Sistema Aquífero Guarani e o Aquífero Alter do Chão. No entanto, a má distribuição deste recurso hídrico é um grande problema. Aproximadamente $81 \%$ das águas doces estão localizadas na Amazônia, onde vivem $5 \%$ da população do país, deixando apenas 19\% da água para o restante das regiões que possuem 95\% da população brasileira (AGÊNCIA NACIONAL DE ÁGUAS, 2015). Na última década, a quantidade de água distribuída aos brasileiros cresceu $30 \%$, mas quase dobrou a quantidade de água sem tratamento (de 3,9\% para 7,2\%), 19 milhões de pessoas que vivem em áreas urbanas não contam com água potável, outras 21 milhões de pessoas que vivem em áreas rurais também não contam com água tratada e apenas $46 \%$ dos domicílios detêm coleta de esgoto. Além de todos estes fatores, o desperdício é alarmante, chega a $45 \%$ de toda a água ofertada pelos sistemas públicos. 
A crise da água também é afetada pela poluição dos cursos hídricos que, além de deteriorar sua qualidade, diminui a quantidade de pontos de captação. Um exemplo é a cidade de São Paulo, que a pesar de receber vários rios, viu a poluição torná-los imprestáveis para o consumo, tendo de captar água de bacias distantes. Em julho de 2014, o Sistema Cantareira de São Paulo enfrentou sua pior crise hídrica nos últimos 80 anos. A falta de chuva aliada à alta demanda, fez com que seu reservatório secasse e fosse preciso usar, pela primeira vez na história, o volume morto da reserva encontrado abaixo do nível do tubo de captação, que conteria os últimos 400 bilhões de litros de água (COHEN, 2015).

As políticas na área ambiental e na área de recursos hídricos no Brasil são produzidas pelo Estado, em que é necessário que haja a identificação de objetivos e a fixação de meios para alcançá-las. A gestão dos recursos hídricos alinhada às normas constitucionais e integrada à gestão ambiental terá como foco resolver as questões de escassez relativa desses recursos e assegurar a oferta de água com qualidade à população compatibilizando as demandas qualitativas e quantitativas com os limites da disponibilidade hídrica e preservando as funções dos ecossistemas.

No estudo da Bacia Hidrográfica do Rio Tramandaí, foram detectados dois problemas ambientais pontuais: (1) a singularidade negativa do balanço hídrico quantitativo nos meses de dezembro a março nas Lagoas Emboaba, Fortaleza e Pombas, onde são feitas retiradas expressivas de água para abastecimento público, irrigação e dessedentação de animais, deixando seus níveis de água baixos nesse período do ano e (2) a poluição da Lagoa do Marcelino Ramos, ocasionada pelo recebimento de todo o esgotamento sanitário da cidade de Osório. 
Para a realização da pesquisa, optou-se pelo estudo qualitativo e o método hipotético dedutivo. O estudo partiu da premissa de que a cooperação federativa (cooperação de natureza contratual entre os entes federativos) é subutilizada na área de recursos hídricos e buscou responder à questão: o emprego da cooperação federativa na bacia hidrográfica do Rio Tramandaí no Rio Grande do Sul pode contribuir na minimização de impactos ambientais e equacionar as questões de escassez desses recursos?

No intuito de resolver o problema de pesquisa buscou-se analisar a possibilidade de emprego da cooperação federativa na Bacia Hidrográfica do Rio Tramandaí. Diante disso, foram coletados dados ambientais e sociais para identificar o cenário em que se encontra a Bacia do Rio Tramandaí. Na coleta de dados, foram utilizados três bancos de dados: (1) Dados do relatório técnico para obtenção de informações complementares e consolidação do diagnóstico elaborado pela empresa Profil Engenharia e Ambiente, juntamente com a Secretaria Estadual do Meio Ambiente (SEMA) e o Departamento de Recursos Hídricos (DRH), (2) Dados do Sistema Nacional de Informações sobre Saneamento (SNIS), e (3) Dados da Fundação Estadual de Proteção Ambiental Henrique Luiz Roessler (FEPAM).

Visando tornar essa abordagem mais objetiva, adotou-se como referência a metodologia proposta em "Gestão dos Recursos Hídricos transfronteiriços " (WATKINS, 2006), em especial os critérios utilizados para identificar a interdependência hidrológica e os requisitos necessários para a cooperação. No capítulo 06 do Relatório de Desenvolvimento Humano (2006) do Programa Nacional das Nações Unidas para o Desenvolvimento (PNUD) é proposta uma metodologia para analisar a possibilidade ou não de uma cooperação em bacias hidrográficas transfronteiriças. No presente artigo, parte-se destas atribuições e utiliza-se as questões "porque coope- 
rar", "como cooperar" e, caso a cooperação seja viável, "como tornar efetiva a cooperação" como norteadoras para analisar a possibilidade de cooperação também em bacias hidrográficas internas.

$\mathrm{Na}$ busca de atingir os objetivos propostos, determinou-se a amplitude da pesquisa na forma de perguntas e respostas que abordam os pontos centrais da gestão de Recursos Hídricos na Bacia do Rio Tramandaí. A coleta de dados serviu para analisar a possibilidade de cooperação na gestão dos recursos hídricos nesta Bacia $\mathrm{Hi}$ drográfica. Buscou-se responder as perguntas que abordam estes pontos: "por que cooperar? " e "como cooperar?".

\section{A Bacia Hidrográfica do Rio Tramandaí: localização e características}

A Bacia Hidrográfica do Rio Tramandaí está localizada no Litoral Norte do Rio Grande do Sul, fazendo parte da Região Hidrográfica do Atlântico Sul, abrangendo uma área de $2700 \mathrm{~km}^{2}$, entre as coordenadas geográficas $29^{\circ} 17^{\prime}$ a $30^{\circ} 18^{\prime}$ de latitude Sul e $49^{\circ} 44^{\prime}$ a $50^{\circ} 24^{\prime}$ de longitude Oeste (CONY, [2014?]). Localiza-se no macro área Nordeste II, contendo 17 municípios participantes: Arroio do Sal, Balneário Pinhal, Capão da Canoa, Cidreira, Dom Pedro de Alcântara, Imbé, Itati, Maquiné, Osório, Palmares do Sul, São Francisco de Paula, Terra de Areia, Torres, Tramandaí, Três Cachoeiras, Três Forquilhas e Xangri-lá (RIO GRANDE DO SUL, 2005c), sendo estes inseridos no COREDE (Conselho Regional de Desenvolvimento da Região Sul) Litoral com 16 municípios; e no COREDE Hortênsias com um município (São Francisco de Paula).

O clima da região da Bacia do Rio Tramandaí é classificado como Cfa (clima subtropical úmido com verões quentes), com temperaturas superiores à $22^{\circ} \mathrm{C}$ no verão e chuva com mais de $30 \mathrm{~mm}$ 
nos meses mais secos de acordo com a classificação de Köppen (sistema de classificação global de tipos climáticos) (KUINCHTNER; BURIOL, 2001). Segundo o Relatório Temático A.2 (2005a, p. 09), "as massas de ar atuantes no Rio Grande do Sul são tropicais marítima (mT), polar marítima ( $\mathrm{mP}$ ) e tropical continental (cT)", as quais são associadas ao anticiclone subtropical, anticiclone móveis polares e a baixa do Chaco. Estas massas de ar, juntamente com o relevo e circulação geral da atmosfera do hemisfério sul, causam uma vasta descontinuidade atmosférica, sendo este o motivo pela grande instabilidade meteorológica da região. Durante o período do primavera e verão (setembro a março), a média da temperatura encontrase entre $20^{\circ} \mathrm{C}$ e $30^{\circ} \mathrm{C}$, no período de outono e inverno (abril a agosto), de $10^{\circ} \mathrm{C}$ a $20^{\circ} \mathrm{C}$.

A bacia hidrográfica do Rio Tramandaí possui uma faixa costeira de aproximadamente $115 \mathrm{~km}$ e uma faixa de drenagem de $2.697,87 \mathrm{~km}^{2}$. Estende-se desde as nascentes dos Rios Maquiné e Três Forquilhas, a oeste, até o norte da Lagoa da Cerquinha (Figura 01) (RIO GRANDE DO SUL, 2005c). A população da Bacia é estimada em 198.235 habitantes, distribuídos entre domicílios urbanos e rurais. Porém, em época de veraneio, a população aumenta cerca de cinco vezes (chega a aproximadamente $10 \%$ da população riograndense) (CONY; BORTOLI; SANTOS, [2014?]).

Todos os rios e lagoas são abastecidos pela nascente do Rio Maquiné, que desemboca na Lagoa dos Quadros, e pela nascente do Rio Três Forquilhas, que desemboca na Lagoa Itapeva. Ambas escoam em direção ao Foz do Rio Tramandaí. Estas duas Lagoas garantem os níveis das demais com escoamento através dos canais de ligação como um grande sistema de vasos comunicantes que permitem a existência de lagoas interligadas, mas também há na 
Bacia do Rio Tramandaí lagoas isoladas (RIO GRANDE DO SUL, 2005).

Devido à conexão com o Oceano Atlântico Sul através da Barra de Tramandaí, existem algumas lagoas que contém água naturalmente salobra - por definição da Resolução do Conselho Nacional do Meio Ambiente (CONAMA) no 357, de 17 de março de 2005, a água denominada salobra deve estar com salinidade compreendida entre $0,50 \%$ e $30 \%$ - sendo elas: Lagoa Gentil, Lagoa das Custódias, Lagoa Armazém Tramandaí, Estuário Rio Tramandaí (RIO GRANDE DO SUL, 2005c).

A Bacia divide-se entre o subsistema Norte (sistema dominante de escoamento), que compreende desde a Lagoa Itapeva até a Lagoa de Tramandaí, e o subsistema Sul de água doce composto pelo conjunto de lagoas desde a Cerquinha até a Lagoa do Manoel Nunes, estas apresentam um volume aproximado de 44 milhões de $\mathrm{m}^{3}$ de água doce. No subsistema sul ainda se encontra a jusante da Lagoa do Manoel Nunes as Lagoas do Gentil e Custódias, ambas de água salobra (RIO GRANDE DO SUL, 2005C)

A Bacia Hidrográfica do Rio Tramandaí (Figura 1) detém de um extenso banhado que ajuda no controle da biodiversidade. As dunas em sua margem funcionam como primeira barreira aos ventos e tempestades oceânicas além de coletar a salinização da água subterrânea (CONY, BORTOLI; SANTOS, [2014?]). 


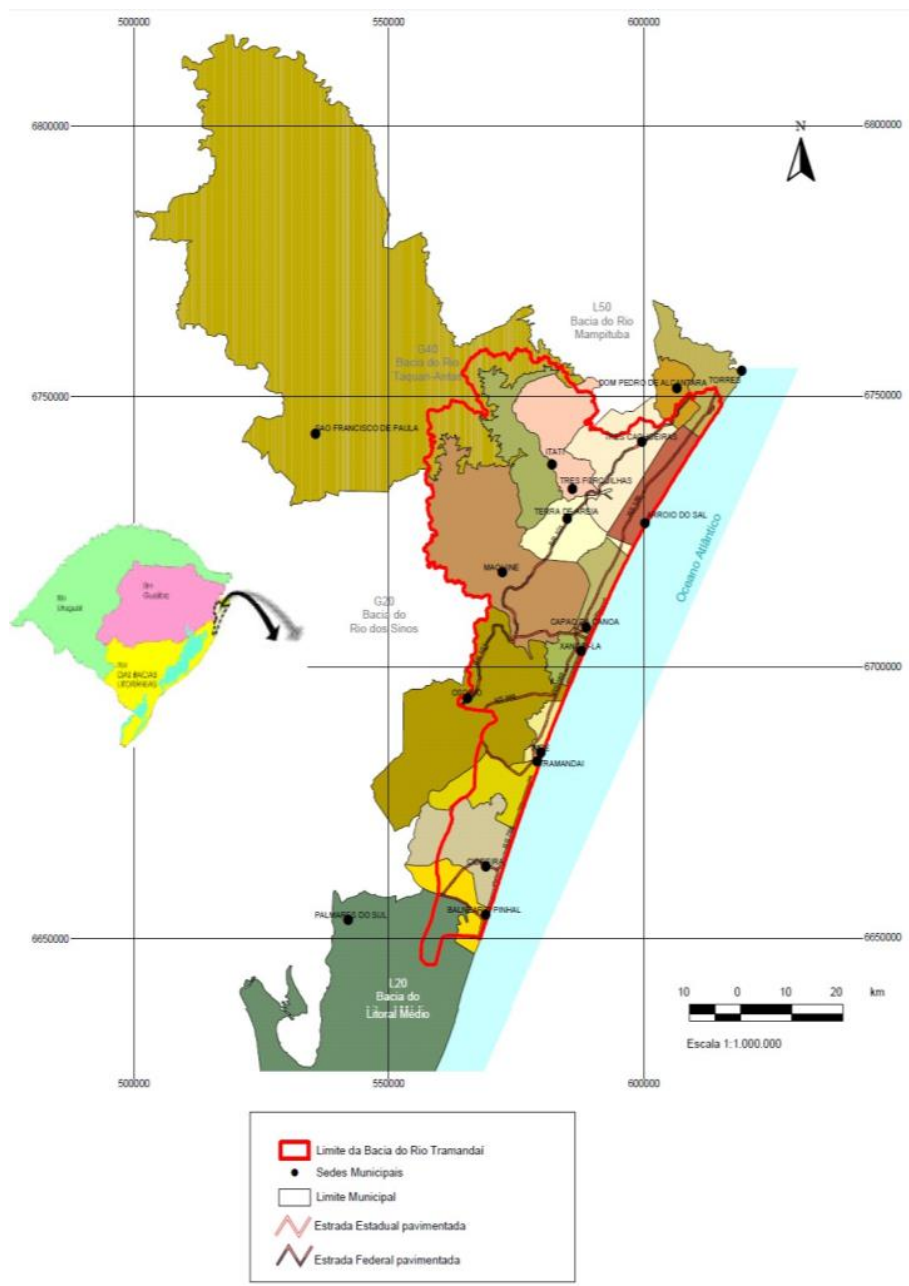

Figura 01 - Localização da Bacia Hidrográfica do Rio Tramandaí.

Fonte: Relatório Temático A.4 (RIO GRANDE DO SUL, 2005c).

Os municípios da bacia movimentam pouco mais de $1 \%$ da economia do Estado. Nesse sentido, destacam-se os municípios de Rev. Elet. Cient. UERGS, v. 3, n. 1, p. 7-38, 2017 
Osório e Palmares do Sul, mesmo não tendo seus municípios na orla. O primeiro destaca-se pelo gênero químico, pelos calçados e produtos alimentares que empregam $84,32 \%$ de sua indústria, e 0 segundo pelo gênero de produtos alimentícios e madeira que empregam $89 \%$ da mão de obra do setor industrial. São esses dois municípios que detêm os maiores investimentos produtivos, tendo no arroz sua cultura principal (RIO GRANDE DO SUL, 2005b).

As águas da Bacia do Rio Tramandaí são utilizadas para: a agricultura irrigada, o abastecimento público, a criação e dessendentação de animais e as indústrias. Além disso, as águas são utilizadas para o comércio, serviços e para pesca (CONY, BORTOLI; SANTOS [2014?]).

O Gerenciamento da Bacia do Rio Tramandaí ocorre através do Comitê da Bacia Hidrográfica do Rio Tramandaí, com sede municipal na cidade de Osório/RS, criado pelo Decreto Estadual no 40.916/2001. É formado por representantes da sociedade e dos usuários das águas da Bacia do Rio Tramandaí, atuando sobre os usos e conservação das águas subterrâneas e superficiais que pertencem à Bacia. É composta por três segmentos da sociedade: os usuários da água (40\%); representantes da população (40\%), e Órgãos Públicos (20\%). O Plano desta Bacia Hidrográfica, que estabelece as metas de qualidade, critérios e as ações quanto ao uso consciente dos recursos hídricos, está incompleto, contendo apenas as fases A (diagnóstico da bacia) e B (cenário de enquadramento) concluídas.

Conforme a Fundação de Proteção Ambiental Henrique Luiz Roesseler (FEPAM), a qualidade de suas águas encontra-se em boa qualidade, com exceção da Lagoa do Marcelino, sendo a mais poluída da Bacia por carregar todo o esgotamento urbano da cidade de Osório. 


\section{Análise e Discussão}

Primeiramente serão examinados os problemas da Bacia do Rio Tramandaí, onde será possível responder a pergunta "por que cooperar? ". Com base na resposta obtida, analisar-se-á a possibilidade do emprego de uma cooperação federativa, se for reconhecível a necessidade de implementá-la, os instrumentos de cooperação serão analisados, procurando o melhor método de resolução dos problemas encontrados.

\section{Porque cooperar?}

A cooperação referente aos recursos hídricos da Bacia Hidrográfica do Rio Tramandaí será considerada sob dois aspectos importantes na avaliação da necessidade de sua obtenção: a interdependência hidrológica e os benefícios da cooperação.

Segundo Justen Filho (2014, p. 288), os fenômenos de cooperações federativas "se tornam cada vez mais evidentes especialmente pelo crescimento das cidades [...]. Surgem questões intermunicipais, inclusive para a prestação conjugada de serviços públicos. " No caso da implementação de cooperação federativa na Bacia $\mathrm{Hi}-$ drográfica do Rio Tramandaí, a utilização da água é a questão intermunicipal a ser analisada.

A interdependência hidrológica é constata porque a água é um recurso circulante e produtivo. A água como recurso produtivo é única na medida em que nunca pode ser gerida para um único uso, ela circula entre os setores e utilizadores. A forma como as águas são utilizadas/manipuladas a montante afetará a qualidade, a regularidade e a quantidade da água para usuários à jusante (WATKINS, 2006). 
Com relação ao uso das águas da Bacia Hidrográfica do Rio Tramandaí, estão relacionados:

a) a agricultura irrigada, basicamente distribuída entre o cultivo de arroz e hortaliças;

b) o abastecimento público, cujo abastecimento e distribuição são promovidos pela Companhia Rio-grandense de Saneamento (CORSAN);

c) a criação e dessedentação de animais, e;

d) as indústrias.

Em época de veraneio, a população quintuplica, trazendo benefícios a economia da região, porém, contribui em parte para a degradação do ambiente e a alta demanda hídrica (Figura 2). Ainda, entre os usos, estão a pesca, o comércio e serviços, com baixo índice de importância (CONY, BORTOLI; SANTOS [2014?]).

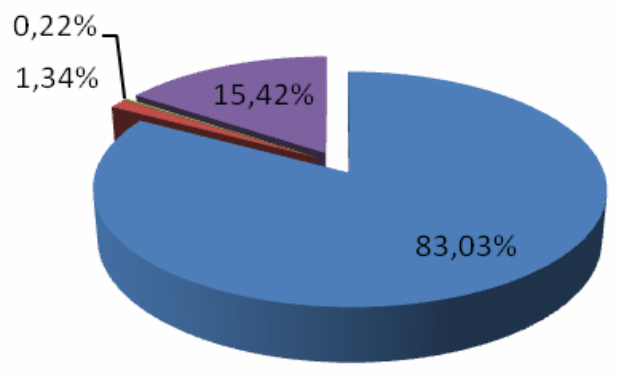

\author{
— Irrigação (92.000.000 \\ $\left.\mathrm{m}^{3} / \mathrm{ano}\right)$ \\ - Criação animal \\ (1.600.000 $\left.\mathrm{m}^{3} / \mathrm{ano}\right)$ \\ Abastecimento Industrial \\ (260.172 $\left.\mathrm{m}^{3} / \mathrm{ano}\right)$ \\ - Abastecimento Público \\ $\left(18.000 \mathrm{~m}^{3} / \mathrm{ano}\right)$
}

Figura 02 - Distribuição do uso da água na Bacia Hidrográfica do Rio Tramandaí.

Com base nesta subdivisão de uso da água da Bacia Hidrográfica do Rio Tramandaí, demonstrada no Gráfico 01, percebe-se a 
maior demanda é pela irrigação (83,03\%), seguida pelo abastecimento público $(15,42 \%)$, criação animal $(1,34 \%)$ e abastecimento industrial $(0,22 \%)$.

A utilização da água da Bacia do Rio Tramandaí para irrigação é destinada principalmente à Rizicultura, onde, no período de dezembro a março atingem, por safra, 92 milhões de metros cúbicos. Além desta cultura, também são cultivadas olericultura e bananais (CONY, BORTOLI; SANTOS, [2014?]).

A demanda hídrica associada à criação e dessedentação de animais é destinada a bovinos, suínos, ovinos, aves e equinos, sendo que o rebanho bovino é o que mais consome água por ano. Além dos animais terrestres, há a aquicultura, que envolve a piscicultura e a carcinicultura, que agregam um montante anual de $1.089 .569 \mathrm{~m}^{3}$ (RIO GRANDE DO SUL, 2005b).

No caso das indústrias, a utilização da água é geralmente feita no processo de limpeza e resfriamento de máquinas. Existem 80 empreendimentos industriais licenciados pela FEPAM de municípios totalmente ou parcialmente inseridos na Bacia do Rio Tramandaí. As indústrias predominantes são Serrarias, Desdobramento de Madeira e Matadouros/ Abatedouros. Segundo dados do Relatório da Fase A (2005), as atividades industriais estão concentradas nos municípios de Osório e Palmares do Sul. O primeiro pelo gênero químico, pelos calçados e produtos alimentares que empregam $84,32 \%$ de sua indústria, já o segundo destaca-se pelo gênero de produtos alimentícios e madeira que empregam $89 \%$ da mão de obra do setor industrial (RIO GRANDE DO SUL, 2004). São esses dois municípios que detêm os maiores investimentos produtivos tendo no arroz sua cultura principal. As indústrias, mesmo monitoradas e com tratamento de efluentes, são responsáveis por gerar carga poluidora, porém, nenhuma indústria da Bacia do Rio Tramandaí encontra-se com eleva- 
do potencial de poluição, já que nenhuma delas encontra-se cadastrada no Sistema de Auto Monitoramento das Indústrias (SISAUTO), que realiza o controle da operação dos sistemas de tratamento de efluentes líquidos das indústrias de maior potencial de poluição hídrica.

Em relação à disponibilidade hídrica, percebe-se que nos meses em que ocorre maior captação dos recursos hídricos (dezembro a março), destacam-se entre as formas de extração das águas da Bacia do Rio Tramandaí a irrigação e o abastecimento público, acarretando a superutilização de alguns mananciais (RIO GRANDE DO SUL, 2005c). Sob aspectos quantitativos, as lagoas que mais sofrem com este fenômeno são as Lagoas do Emboaba, da Fortaleza e das Pombas, que apresentam um nível hídrico consideravelmente baixo neste período.

$\mathrm{Na}$ Lagoa do Emboaba, seu pequeno volume associado à grande captação anual de água para o abastecimento público e a criação de animais e sazonal (dezembro a março) para a irrigação explica esta singularidade negativa do balanço hídrico quantitativo. Entre os meses de dezembro a fevereiro, época de irrigação e veraneio, a demanda pela água ultrapassa o limite de disponibilidade hídrica, já em março é utilizado entre 60 e 100\% da capacidade. No restante do ano, explora-se aproximadamente $40 \%$ de sua disponibilidade apenas para o abastecimento público. Com isso, essa lagoa apresenta uma situação desfavorável durante o ano todo em relação à quantidade de água armazenável, mesmo contendo um nível elevado de recuperação durante o período de menos demanda (abril a outubro).

A Lagoa da Fortaleza apresenta níveis baixos nos meses de dezembro a fevereiro, por estarem associadas à captação de água para a irrigação e abastecimento público, ultrapassando seus limites 
de disponibilidade hídrica. Nos meses de novembro a março ocorre a utilização de 30 a $60 \%$ de água. No restante do ano (abril a outubro) a captação deste recurso não chega e 5\%, o que facilita a recuperação dos reservatórios (RIO GRANDE DO SUL, 2005a). Na Lagoa das Pombas, o período de balanço hídrico desfavorável é de dezembro a fevereiro, pois aumenta a demanda para a irrigação, ultrapassando seu limite de disponibilidade. Esta lagoa não é utilizada para o abastecimento público, o que se faz visível sua maior facilidade em recuperar sua disponibilidade hídrica. No mês de março, utiliza-se de 30 a $60 \%$ de sua disponibilidade. No restante do ano, o número de captação não atinge 1\% (RIO GRANDE DO SUL, 2005a).

Diante disto, com exceção da Lagoa do Emboaba, a situação desfavorável de balanço hídrico na Bacia Hidrográfica do Rio Tramandaí é sazonal (dezembro a março) com período de recuperação nos meses de outono, inverno e primavera, não havendo comprometimento da manutenção a longo prazo.

No restante das Lagoas pertencentes à Bacia Hidrográfica do Rio Tramandaí não é identificada nenhum problema com escassez hídrica. Os usos relacionados às demais lagoas dividem-se entre abastecimento público, irrigação de lavouras, criação e dessedentação de animais, sendo que nunca há os três usos ao mesmo tempo, e ainda, algumas não fornecem água para nenhum dos usos. As lagoas de água salobra (Lagoas Gentil, Custódia e Tramandaí/Armazém) não tem nenhum tipo de extração, mas são usadas geralmente para recreação primária, secundário e/ou paisagística, dependendo da sua classificação de qualidade de água, fornecida pela CONAMA (RIO GRANDE DO SUL, 2005b).

Analisando essas informações, os recursos hídricos da bacia são disputados por vários atores: a população, os agricultores, os Rev. Elet. Cient. UERGS, v. 3, n. 1, p. 7-38, 2017 
pecuaristas e as indústrias. Usos inadequados dos recursos hídricos afetam todos os atores de montante para jusante, já que as atividades humanas sobre o ambiente resultam em efluentes com repercussões diretas sobre a qualidade dos recursos hídricos.

As águas da Bacia do Rio Tramandaí recebem cargas poluidoras de origem doméstica e animal. $O$ tratamento de esgoto em forma de fossas é predominante ( $80 \%$ das moradias). Considerando os municípios de maior desenvolvimento, apenas cinco contém rede coletora de esgoto: Capão da Canoa, Cidreira, Osório, Tramandaí e Xangri-lá. Destes, Osório não tem estação de tratamento de esgoto. Por ano, estima-se que são lançados nos corpos hídricos 4.439 toneladas de carga poluidora orgânica. Existem cinco depósitos de resíduos sólidos urbanos licenciados pela FEPAM, localizados nas cidades de Terra de Areia, Osório, Capão da Canoa, Tramandaí e Três Cachoeiras. Os municípios que não os têm, enviam seus rejeitos para os municípios de Tramandaí e Terra de Areia (CONY, BORTOLI; SANTOS, [2014?]).

A caracterização da qualidade das águas superficiais da Bacia do Rio Tramandaí é feita a partir dos padrões estabelecidos na Resolução CONAMA, conforme os artigos $4^{\circ}$ e $6^{\circ}$ da resolução $357 / 2005$, distintas entre águas doces (salinidade igual ou inferior a $0,5 \%$ ); águas salobras (salinidade superior a 0,5\% e inferior a 30 $\%$ ), e águas salinas (salinidade igual ou superior a $30 \%$ ).

Conforme denominação do CONAMA, as classes de qualidade das águas doces são classificadas em classes especial, classes 1, 2, 3 e 4, sendo as classes especial, 1 e 2 de qualidade ótima e boa e classes 3 e 4 de qualidade ruim a péssima.

As lagoas classificadas como classe 1, segundo a classificação para águas doces são: Lagoa dos Quadros, Lagoa das Malvas, Lagoa do Palmital, Lagoa da Pinguela, Lagoa do Peixoto, Lagoa da 
Fortaleza, Lagoa da Cidreira, Lagoa Rondinha e Lagoa da Cerquinha.

A Lagoa Itapeva é classificada como classe 2 de água doce. Essa lagoa recebe esgoto sanitário, porém, por conter grande extensão, a carga poluidora acaba sendo diluída.

A Lagoa do Marcelino é de classe 4 para água doce. Esta lagoa é a mais preocupante em relação a sua qualidade, pois é uma lagoa rasa sem influência salina interligada pelo sistema fluvial lacustre do Rio Tramandaí por canais de ligação. Recebe em sua margem sul a entrada de esgotos cloacais da cidade de Osório, o que explica sua classificação 4. Além do esgoto, há a ocupação desordenada de sua margem e supressão de Áreas de Proteção Permanente (APPs) e enterro desordenado de lixo no solo pela população ou até mesmo a céu aberto. Porém, a situação desfavorável de poluição da lagoa do Marcelino não afeta a qualidade da água da Lagoa do Peixoto, que se encontra a seu montante.

O município de Osório capta água para abastecimento público da Lagoa do Peixoto, que detém classe 1, e de poços subterrâneos supervisionados pela Vigilância Sanitária, o que pode explicar a sua deposição de esgoto na Lagoa do Marcelino. A Lagoa das Custódias e a Lagoa do Gentil são de Classe 7 para águas salobras, que podem ser destinadas a recreação de contato primário, proteção de comunidades aquáticas, criação de espécies destinadas a alimentação humana. A Lagoa de Tramandaí e a Lagoa do Armazém são de Classe 8 de águas salobras, destinadas à navegação, à harmonia paisagística e a recreação de contato secundário. O restante das lagoas tem suas águas em boa qualidade, contendo classificação 1.

A Figura 03 demonstra, com fácil visualização, a classificação da qualidade das águas da Bacia do Rio Tramandaí, conforme Resolução CONOMA 357/2005. 


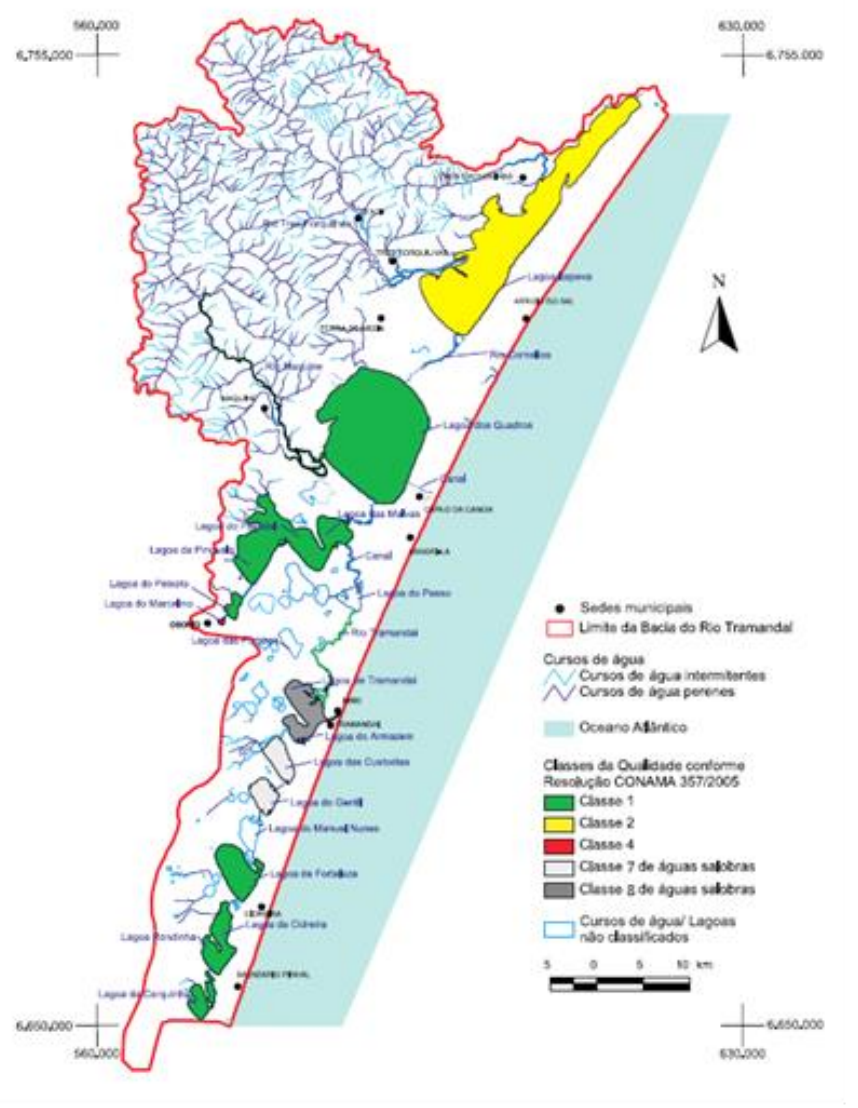

Figura 03 - Classificação das águas da Bacia Hidrográfica do Rio Tramandaí. Fonte: Cony, Bortoli e Santos ([2014?]).

O Relatório da Fase B de Consolidação do Enquadramento das Águas Superficiais da Bacia do Rio Tramandaí propõe intervenções de melhoria da qualidade dos cursos hídricos da Bacia. Com base nisto, as lagoas que detêm água salobra de classificação 8 
seriam melhoradas para a classificação 7, a Lagoa do Itaipeva continuaria com classificação 2 de água doce, a Lagoa do Marcelino (mais degradada) seria melhorada de classe 4 para 3, e o restante das lagoas serão melhoradas para classe 1 (as que necessitarem).

As intervenções a serem feitas para a melhora da qualidade das águas da Bacia do Rio Tramandaí, de acordo com o Relatório da Fase B (RIO GRANDE DO SUL, 2005d) seriam:

a) as lagoas/rios que tiverem classe 1, seriam feitos monitoramentos de qualidade para que pudesse ser mantida esta classe;

b) nos pontos onde há deficiência na coleta e saneamento de esgoto, seriam implementadas/ampliadas as redes de tratamento, coleta e saneamento de esgoto para a resolução do problema de poluição dos cursos hídricos, além de intensificar a fiscalização dos padrões de emissão das indústrias;

c) na Lagoa Emboaba que apresenta déficit hídrico, seriam avaliadas lagoas alternativas para poder dividir a extração de água conforme for necessário;

d) reduzir os rebanhos para que possa diminuir a deposição de resíduos sólidos nas lagoas, onde mostra-se mais afetada a Lagoa Itaipeva, que a partir desta iniciativa, poderia apresentar melhora na qualidade da água;

e) manutenção do aterro sanitário de Terra de Areia para poder atender em melhores condições a coleta de resíduos sólidos urbanos dos municípios que a ocupam;

f) remoção do lodo (material orgânico) depositado no fundo da Lagoa do Marcelino, separação total das coletas pluvial e cloacal, permitindo somente pluvial para diluição para que possa melhorar de classe 4 para 3, inicialmente; 
g) controlar a deposição de agrotóxicos provenientes das lavouras para obtenção da diminuição da poluição dos cursos hídricos;

h) nas águas salinas estariam sendo feitos monitoramentos de qualidade e salinização principalmente nas épocas de seca onde a salinização da água aumenta, o que é percebido pela CORSAN ao captar água para abastecimento público;

i) fiscalização das APPs.

j) a recuperação da mata ciliar e o monitoramento da qualidade das águas da Bacia do Rio Tramandaí estão previstos para todos os tipos de curso hídrico.

A competição por água e o impacto na sua qualidade são constatações que caracterizam a interdependência hidrológica na Bacia Hidrográfica do Rio Tramandaí. Essa é a primeira causa identificada para implantar a cooperação federativa. Outra causa importante é o custo/benefício da cooperação. Para que seja aprovada sua criação, a relação custo-benefício advinda desta devem ser examinados, onde os benefícios devem superar os custos. Nesse sentido, todas as políticas, programas e ações estatais devem assegurar o máximo ganho social.

No trato da relação custo-benefício serão examinadas as questões de saneamento básico e resíduos sólidos. Para isso serão usados os dados da pesquisa realizada pelo Sistema Nacional de Informações sobre Saneamento (SNIS), referente ao diagnóstico dos serviços de água e esgoto do ano de 2013, onde serão filtrados os municípios da Bacia Hidrográfica do Rio Tramandaí que responderam o questionário (Tabela 1). Dos dezessete (17) municípios participantes da Bacia do Rio Tramandaí, cinco (5) responderam a pesquisa. 
Tabela 01 - Respostas obtidas pela pesquisa do Sistema Nacional de Informações sobre Saneamento (SNIS) de 2013.

\begin{tabular}{cccc|ccc}
\hline Municipios & Serviço & $\begin{array}{c}\text { Plano } \\
\text { Municipal de } \\
\text { Saneamento? }\end{array}$ & $\begin{array}{c}\text { Metas do Plano estão sendo } \\
\text { alcançadas? } \\
\text { Abastecimento } \\
\text { de água }\end{array}$ & $\begin{array}{c}\text { Esgotamento } \\
\text { sanitário }\end{array}$ & $\begin{array}{c}\text { Integrante de } \\
\text { consórcios nas } \\
\text { áreas de água e } \\
\text { esgoto? }\end{array}$ & $\begin{array}{c}\text { Coleta de } \\
\text { Resíduos } \\
\text { sólidos }\end{array}$ \\
\hline $\begin{array}{c}\text { Balneário } \\
\text { Pinhal }\end{array}$ & Esgoto & Sim & Sim & $\begin{array}{c}\text { Vigência do plano } \\
\text { posterior à } \\
\text { pesquisa } \\
\text { Sem resposta }\end{array}$ & Não & Diariamente \\
\hline $\begin{array}{c}\text { Imbé } \\
\text { Osório }\end{array}$ & Esgoto & Em elaboração & Sem resposta & Semosto & Sem resposta \\
\hline $\begin{array}{c}\text { Palmares } \\
\text { do Sul }\end{array}$ & Esgoto & Sim & Vigência do plano posterior à pesquisa & Não & Diariamente \\
$\begin{array}{c}\text { Três } \\
\text { Cachoeiras }\end{array}$ & Esgoto & Sim & Sim & $\begin{array}{c}\text { Vigência do plano } \\
\text { posterior à } \\
\text { pesquisa }\end{array}$ & Não & Sem resposta \\
\hline
\end{tabular}

Fonte: Adaptado de SNIS (2014).

De acordo com os dados obtidos pelo SNIS, o Quadro 01 demonstra que há certa dificuldade no cumprimento das metas dos planos, tanto de água e esgotamento sanitário quanto à coleta de resíduos sólidos. Dos 17 municípios participantes da Bacia Hidrográfica do Rio Tramandaí, apenas cinco responderam à pesquisa, e destes, três tem plano municipal de saneamento, porém não cumprem a meta dos dois requisitos de qualidade (água e esgoto). Em relação à coleta de resíduos sólidos, apenas Osório e Balneário Pinhal responderam à pesquisa, declarando recolhê-los diariamente. O munícipio de Palmares do Sul, um dos municípios mais desenvolvidos da bacia que concentra $89 \%$ da mão de obra do setor industrial da Bacia do Rio Tramandaí, não disponibiliza serviços de saneamento e resíduos sólidos. 


\section{Como cooperar?}

A Lei Complementar № 140 de 8 de dezembro de 2011, tem o objetivo de fixar normas, nos termos dos incisos III, VI e VII do caput e do parágrafo único do art. 23 da Constituição Federal de 1988, para a cooperação entre a União, os Estados, o Distrito Federal e os Municípios nas ações administrativas decorrentes do exercício da competência comum relativas à proteção das paisagens naturais notáveis, à proteção do meio ambiente, ao combate à poluição em qualquer de suas formas e à preservação das florestas, da fauna e da flora. No Capítulo II, artigo 4º desta Lei Complementar dispõe os instrumentos de cooperação:

I - consórcios públicos, nos termos da legislação em vigor;

II - convênios, acordos de cooperação técnica e outros instrumentos similares com órgãos e entidades do Poder Público, respeitado o art. 241 da Constituição Federal;

III - Comissão Tripartite Nacional, Comissões Tripartites Estaduais e Comissão Bipartite do Distrito Federal;

IV - fundos públicos e privados e outros instrumentos econômicos;

V - delegação de atribuições de um ente federativo a outro, respeitados os requisitos previstos nesta Lei Complementar; VI - delegação da execução de ações administrativas de um ente federativo a outro, respeitados os requisitos previstos nesta Lei Complementar (BRASIL, 2011).

No que tange às bacias hidrográficas, os consórcios públicos e os convênios de cooperação são amplamente utilizados, sendo que possa ser viabilizada estas ações entre os entes federativos participantes da Bacia do Rio Tramandaí (BRASIL, 2005). De acordo com Justen Filho (2014, p.286):

considera-se consórcio público a pessoa jurídica formada exclusivamente por entes da federação [...] para estabelecer relações de cooperação federativa [...] constituída como associ- 
ação pública, com personalidade jurídica de direito público e natureza autarquia ou como pessoa jurídica de direito privado sem fim lucrativo.

Levando em consideração que o Comitê da Bacia é ativo e atuante e que os problemas encontrados na Bacia do Rio Tramandaí são pontuais (o esgotamento sanitário de Osório) e sazonais (demanda hídrica no verão com recuperação nos meses de outono e de inverno), a cooperação mediante a formação de consórcio público entre os municípios englobantes da Bacia Hidrográfica do Rio Tramandaí, trata-se de uma alternativa em que a relação do custo/benefício mostra-se desfavorável ao máximo ganho social, sendo portanto desaconselhável sua utilização neste cenário.

Em relação à baixa disponibilidade hídrica nos meses de irrigação agregado a alta demanda pelo abastecimento público, algumas práticas deveriam ser adotadas para amenizar este problema:

a) reduzir a utilização dos Recursos Hídricos no meio rural, através de formas de conscientização da população, utilizando a educação ambiental;

b) regularizar a situação das Estações de Tratamento de Água (ETA) de Osório, podendo assim implementar um Centro de Controle Operacional (CCO), a qual funciona a partir de um sistema de automação por telemetria implantado a esta ETA. Este aparelho monitorará em tempo real o sistema de distribuição de água, permitindo o controle eficiente e constante da pressão nas redes. Com esta tecnologia, será possível detectar os pontos de vazamento e ligações clandestinas, diminuindo o desperdício de água;

c) organizar um cronograma onde identifique o horário de maior captação de água para a irrigação e saneamento básico, esta- 
belecendo um horário preferencial onde estas duas formas de captação não colidam, dando maior espaço de tempo para que haja reposição do manancial;

d) estudar fontes de utilização de reuso de água.

Além destas possíveis vias de recuperação dos recursos hídricos, o Relatório Temático B.1 (RIO GRANDE DO SUL, 2005e) indica algumas soluções viáveis para resolver os problemas a longo prazo como: (1) implementação de projetos de recuperação das matas ciliares; (2) implementação/ampliação do programa de monitoramento hidroclimatológico; (3) implementação de um projeto de redução de perdas no abastecimento público, conforme detalhado no item $b$ das sugestões para amenizar o problema de disponibilidade hídrica.

Muitas Áreas de Preservação Permanente (APP's) foram utilizadas para plantio, sendo este considerando o principal fator causador da degradação ambiental dos mananciais. Pensando na resolução deste tipo de empasse, o Estado do Rio Grande do Sul criou o Programa de Restauração e Conservação das Matas Ciliares, elaborado como atividades do Departamento de Florestas e Áreas Protegidas da Secretaria Estadual do Meio Ambiente (DEFAP/SEMA), com o intuito de promover a conservação dos mananciais hídricos, estimulando a restauração e preservação das áreas de AAPs, garantindo a qualidade e quantidade da água à população, no período de médio e longo prazo. Este ato está programado para atender todas as suas 25 Bacias Hidrográficas. O Comitê Tramandaí tem aprovada a vontade de incluir-se neste programa, mas ainda não sagrou sucesso efetivo no início de sua implementação, sendo que é registrado na bibliografia apenas o Projeto Recuperação de Áreas Degradadas da Sub-bacia do Rio Maquiné, realizado pela ANAMA, 
com patrocínio da Petrobras, através do Programa Petrobras Ambiental (POESTER et al., 2012), onde há a parceria com a Bacia $\mathrm{Hi}$ drográfica do Rio Tramandaí, pois parte do Rio Maquiné passa entre a Lagoa dos Quadros e as Lagoas Malvas e Palmital.

Segundo o Relatório da Fase B (2005d), na Bacia Hidrográfica do Rio Tramandaí ao longo do Rio Maquiné e do Rio Três ForquiIhas, devem ser recuperados 20 mil metros lineares de mata ciliar que foram degradadas pela agricultura exposta. Ao longo do Rio Tramandaí, a agricultura atingiu 5 mil metros lineares. O custo de recuperação de uma área degradada é de 20 mil reais por hectare. Considerando uma faixa marginal de 30 metros ao longo dos cursos d'água, significam aproximadamente $R \$ 60$ reais por metro linear de mata ciliar.

O comitê de Bacia ainda sugere a implementação/ampliação das redes de monitoramento hidroclimatológicas, onde possibilitaria o melhor conhecimento das capacidades hídricas na região, podendo calcular a prevenção e redução das perdas por fenômenos hidrológicos externos (cheias e secas), além de permitir a maior segurança nas decisões referentes a projetos e obras, os quais serão dimensionados adequadamente, sem que haja superdimensionamento ou subdimensionamento de estruturas. A relação custo/beneficio da implementação/ ampliação das redes de monitoramento é significativamente superior a um. Estudos feitos na Austrália e no Canadá apresentam a relação de que para cada $R \$ 1$ real investido, tem-se retorno de $R \$ 6,40$ a $R \$ 9,30$ reais (RIO GRANDE DO SUL, 2005d).

De acordo com o Relatório da Fase B (RIO GRANDE DO SUL, 2005d), em relação às perdas obtidas na distribuição de água através do abastecimento público, houve uma diferença média de cerca de $37 \%$ entre o volume de água produzido e o volume de água comercializado (consumido). Estas perdas originam-se de 
vazamentos no sistema envolvendo captação, adução de água bruta, tratamento, reserva e a distribuição desta água coletada, além de procedimentos operacionais como lavagens de filtros e descargas nas redes quando estes provocam consumos superiores ao estritamente necessário para obtenção.

Segundo a Associação Brasileira de Engenharia Sanitária e Ambiental (2013), o objetivo de um programa de redução de perdas no sistema de abastecimento é reduzir o volume de água captado, produzindo uma quantidade menor de água para abastecer a mesma quantidade de pessoas. Esta ação implicaria na redução de custos em alguns fatores, tais como: produtos químicos investidos no tratamento da água a ser distribuída, energia elétrica (menos água produzida necessita de menos energia para a execução do trabalho) e mão de obra. A troca de hidrômetros e mediadores, corte nas ligações fraudulentas e a melhora no cadastro do usuário também beneficiaria a redução nas perdas no sistema de abastecimento, de modo a haver maior controle na sua distribuição, identificando os problemas com maior agilidade.

Analisando todos estes fatores, pode-se perceber que se as perdas relacionadas ao abastecimento público fossem controladas ou exterminadas isso significaria uma contribuição para o não desperdício de água potável.

A Lagoa Emboaba é a mais atingida pela competição pela água entre a irrigação e o abastecimento público, onde praticamente seca neste período do ano (dezembro a março). A alternativa mais viável seria a busca por outro manancial. Consta que, $75 \%$ da disponibilidade calculada é utilizada pela CORSAN para o abastecimento público de Tramandaí (RIO GRANDE DO SUL, 2005d). Diante disto, o procedimento cabível seria não utilizar esta lagoa para a irrigação, deixando-a somente para abastecimento público, buscan- 
do outro manancial superficial para atender a irrigação. Uma alternativa seria estudar a possibilidade de utilizar a Lagoa do Biguá para a irrigação, pois ela é visualmente parecida com a Lagoa do Emboaba em relação a sua forma e tamanho. Para aprovação desta alternativa, necessita-se a realização de um estudo sobre sua capacidade de fornecer água e o custo a ser empregado para a realização deste evento, visto que se trata de uma lagoa isolada, como a Lagoa do Emboaba, o que aumenta sua fragilidade.

Com base nos dados analisados, percebe-se que os custos de recuperação dos cursos hídricos e de sua vegetação ao longo dos rios e lagos são baixos. Com isso, uma cooperação seria um empreendimento exagerado para a demanda encontrada. Como os problemas são pontuais e sazonais (dezembro a março) e envolvem o esgotamento sanitário de Osório, cabe ao Ministério Público protocolar Ação para que o Município e a CORSAN realizem as obras necessárias para a construção de uma Estação de Tratamento de Esgoto (ETE) e a despoluição da Lagoa Marcelino Ramos, que recebe os esgotos cloacais da cidade de Osório. 


\section{Conclusão}

Baseado nos estudos realizados na Bacia Hidrográfica do Rio Tramandaí, a poluição da Lagoa Marcelino Ramos, causado pela deposição dos esgotos cloacais da cidade de Osório e a singularidade negativa no balanço hídrico na Lagoa Emboaba, resultante da sobrecarga da utilização da água ocasionada pela agricultura irrigada e o abastecimento público da cidade de Tramandaí foram os principais problemas detectados na região, sendo estes pontuais/sazonais (dezembro a março).

Analisando estes casos e levando em consideração as formas de cooperação estabelecidas pela Lei Complementar $n^{\circ} 140$ de 8 de dezembro de 2011, capítulo II, artigo $4^{\circ}$, verificou-se, diante aplicação do método, que um Consórcio Público ou um Convênio de Cooperação seriam investimentos desnecessários para as demandas exigidas, pois a relação custo/benefício mostrou-se desfavorável. Salienta-se que o Comitê de Bacia do Rio Tramandaí é ativo e atuante.

Diante disso, Ações dos Órgãos ambientais de fiscalização mostram-se necessárias para que obras de tratamento do esgoto doméstico e a despoluição da Lagoa do Marcelino Ramos sejam realizadas. No caso da Lagoa Emboaba, a melhor solução encontrada implica dividir a extração entre esta e a Lagoa do Biguá (visualmente compatível com a Lagoa Emboaba), deixando somente o abastecimento público para a primeira, e a segunda encarregar-seia das demais atividades. 


\section{Referências}

ASSOCIAÇÃO BRASILEIRA DE ENGENHARIA SANITÁRIA E AMBIENTAL. Perdas em Sistemas de Abastecimento de água: diagnóstico, potencial de ganhos com sua redução e proposta de medidas para o efetivo combate. Porto Alegre: ABES, 2013. Disponível em: < http://www.abes-sp.org.br/arquivos/perdas.pdf>. Acesso em: 14 set. 2016.

AGÊNCIA NACIONAL DAS ÁGUAS. ANA divulga relatório de Conjuntura dos Recursos Hídricos no Brasil - Informe 2014. Brasília: ANA, 2015. Disponível em: < http://www2.ana.gov.br/Paginas/imprensa/noticia.aspx?id_noticia $=12$ 683>. Acesso em: 15 dez. 2015.

BRASIL. Constituição (1988). Constituição da República Federativa do Brasil de 1988. Disponível em:

$<$ http://www.planalto.gov.br/ccivil 03/constituicao/constituicaocompil ado.htm>. Acesso em: 10 mar. 2015.

\section{. Lei Complementar n 140, de 8 de Dezembro de 2011.}

Dispõe sobre fixar normas, nos termos dos incisos III, VI e VII do caput e do parágrafo único do art. 23 da Constituição Federal, para a cooperação entre a União, os Estados, o Distrito Federal e os Municípios nas ações administrativas decorrentes do exercício da competência comum relativas à proteção das paisagens naturais notáveis, à proteção do meio ambiente, ao combate à poluição em qualquer de suas formas e à preservação das florestas, da fauna e da flora. Disponível em:

$<$ http://www.planalto.gov.br/Ccivil 03/leis/LCP/Lcp140.htm>. Acesso em: 03 dez. 2014.

. Lei 11.107 de 06 de abril de 2005. Dispõe sobre normas gerais de contratação de consórcios públicos e dá outras providências. Disponível em <http://www.planalto.gov.br/ccivil 03/ ato20042006/2005/lei/l11107.htm> Acesso em 15 de fev. 2015. 
COHEN, O. O Fundo do Poço. [2014?]. Disponível em: < http://super.abril.com.br/crise-agua/ofundodopoco.shtml>. Acesso em: 07 mar. 2015.

CONY, S.; BORTOLI, C. R.; SANTOS, E. R. Plano de Bacia Hidrográfica do Rio Tramandaí. Osório: Comitê Tramandaí, [2014?].

Disponível em:

<http://www.comitetramandai.com.br/files/plano_bacia_hidrografica_ rio_tramandai.pdf >. Acesso em: 30 out. 2014.

CONSELHO NACIONAL DO MEIO AMBIENTE. Resolução n 357, de 17 de março de 2005. Dispõe sobre a classificação dos corpos de água e diretrizes ambientais para o seu enquadramento, bem como estabelece as condições e padrões de lançamento de efluentes, e dá outras providências. Disponível em: < http://www.mma.gov.br/port/conama/res/res05/res35705.pdf> Acesso em: 19 nov. 2014.

CURI, D. Gestão Ambiental. São Paulo: Geográfica, 2010.

JUSTEN, M. F. Curso de Direito Administrativo. 10. ed. São Paulo: Revista dos Tribunais, 2014.

KUINCHTNER, A.; BURIOL, G.A. Clima do estado do Rio Grande do Sul segundo a classificação climática de Köppen e Thornthwaite.

Disciplinarum Scientia: Série: Ciências Exatas, Santa Maria, v. 2, n. 1, p.171-182, nov. 2001.

POESTER, G.C. et al. Práticas para restauração da mata ciliar. Porto Alegre: Catarse, 2012.

RIO GRANDE DO SUL. Secretaria Estadual Do Meio Ambiente. Departamento De Recursos Hídricos. Relatório da Fase A: Consolidação do Diagnóstico e Balanço Hídrico da Bacia Hidrográfica do Rio Tramandaí. Porto Alegre: [s.n.], 2005.

Relatório Técnico A.1: Diagnóstico da Dinâmica Social da Bacia. Porto Alegre: [s.n.], 2004. 
.. Relatório da Fase A.2: diagnóstico das disponibilidades. Porto Alegre: [s.n.], 2005a.

. Relatório Técnico A.3: diagnósticos e prognósticos das demandas hídricas. Porto Alegre: [s.n.], 2005b.

Relatório Técnico A.4: organização e condução da mobilização social. Porto Alegre: [s.n.], 2005c.

. Relatório da Fase B: consolidação da fase de enquadramento dos recursos hídricos superficiais. Porto Alegre: [s.n.], 2005d.

. Relatório Temático B.1: alternativas de compatibilização das disponibilidades quantitativas e demandas hídricas. Porto Alegre: [s.n.], 2005e.

WATKINS, K. et al. (Ed). Gestão dos Recursos Hídricos Transfronteiriços. In: ORGANIZAÇÃO DAS NAÇÕES UNIDAS. Relatório do Desenvolvimento Humano (IA) 2006: A água para lá de escassez: poder, pobreza e a crise mundial da água. New York: PNDU, 200 